\title{
Acute myocardial infarction and infarct size: do circadian variations play a role?
}

\author{
This article was published in the following Dove Press journal: \\ ChronoPhysiology and Therapy \\ 28 August 2012 \\ Number of times this article has been viewed
}

\section{Aída Suárez-Barrientos' Borja Ibáñez ${ }^{1,2}$ \\ 'Cardiovascular Institute, Hospital Clínico San Carlos, ${ }^{2}$ Centro Nacional de Investigaciones Cardiovasculares, Madrid, Spain}

\begin{abstract}
The circadian rhythm influences cardiovascular system physiology, inducing diurnal variations in blood pressure, heart rate, cardiac output, endothelial functions, platelet aggregation, and coronary arterial flow, among other physiological parameters. Indeed, an internal circadian network modulates cardiovascular physiology by regulating heart rate, metabolism, and even myocyte growth and repair ability. Consequently, cardiovascular pathology is also controlled by circadian oscillations, with increased morning incidence of cardiovascular events. The potential circadian influence on the human tolerance to ischemia/reperfusion has not been systematically scrutinized until recently. It has since been proven, in both animals and humans, that infarct size varies during the day depending on the symptom onset time, while circadian fluctuations in spontaneous cardioprotection in humans with ST-segment elevation myocardial infarction (STEMI) have also been demonstrated. Furthermore, several studies have proposed that the time of day at which revascularization occurs in patients with STEMI may also influence infarct size and reperfusion outcomes. The potential association of the circadian clock with infarct size advocates the acknowledgment of time of day as a new prognostic factor in patients suffering acute myocardial infarction, which would open up a new field for chronotherapeutic targets and lead to the inclusion of time of day as a variable in clinical trials that test novel cardioprotective strategies.
\end{abstract}

Keywords: cardioprotection, circadian rhythm, reperfusion injury, ST-segment elevation myocardial infarction

\section{Introduction}

The identification of the factors involved in the modulation of cardiovascular pathophysiology holds the potential to limit damage during an acute myocardial infarction (AMI). The variables that predict clinical events (eg, mortality and other relevant outcomes) are the subject of intense research efforts that aim to better stratify patients after an AMI, and to investigate novel therapies to improve long-term prognoses. The extent of myocardial necrosis has been recently described as one of the strongest predictors of mortality and morbidity after an ST-segment elevation myocardial infarction (STEMI). ${ }^{1}$ Therefore, infarct size has become the endpoint of STEMI clinical trials as a surrogate marker of hard clinical endpoints. ${ }^{2}$

It is well established that the circadian rhythm modulates cardiovascular physiology, influencing risk factors such as blood pressure and heart rate, but also other processes that play an important role in myocardial pathological events, such as myogenic tone, endothelial function, and circulating levels of humoral factors. Given this association, it is not difficult to understand that cardiovascular events may also be affected by 
circadian patterns. Numerous studies have evaluated the impact of time of day on STEMI incidence, concluding that there are more incidences around the sleep-to-wake transition. ${ }^{3}$ With this body of evidence on the role of circadian rhythms on cardiovascular conditions, it seems intuitive to predict that the former might play a role in the pathophysiology of AMI and could modulate the heart response of ischemic insults. Related evidence has emerged recently both in animal and human studies, suggesting larger infarct sizes during specific periods of the day. ${ }^{4,5}$ These findings open the door for a new variable - the chronology of AMI onset - to be considered in order to determine prognosis after AMI and included as a new variable in clinical trials testing novel cardioprotective strategies, as well as for a new therapy target to be explored.

\section{The circadian clock and the cardiovascular system}

Mammalian daily rhythms are regulated by a pacemaker within the suprachiasmatic nuclei of the hypothalamus, called the circadian clock. This biological system consists of a combination of genes and proteins that behave in a cyclical way following a 24-hour pattern. ${ }^{6}$ It is not only governed by endogenous factors, but also by environmental stimuli, the most important of which is the dark-light cycle. This structure controls the biochemical, metabolic, physiological, and behavioral processes of mammals, including the cardiovascular system. ${ }^{7,8}$

The circadian clock operates in both the central and peripheral nervous systems in order to regulate local, specific functions. A temporal dependence of cardiovascular physiology has been progressively demonstrated. The cardiovascular system follows circadian variations driven by humoral signs. Cortisol and epinephrine levels increase during the morning period and fall during sleep, and both are considered one of the main humoral signs that connect the circadian clock and peripheral system activity. ${ }^{9-11}$ Aldosterone and plasma renin activity also follow circadian patterns, being higher in the morning and modulating the cardiovascular system. ${ }^{12,13}$ The circadian clock also controls melatonin production at the pineal gland. ${ }^{14}$ This hormone influences the circadian rhythm by a negative feedback mechanism, regulating circadian physiology. Simultaneously, melatonin influences cardiovascular pathophysiology by a double mechanism, binding melatonin receptors present throughout the vascular system and heart, and acting directly as an antioxidant factor. ${ }^{15}$ Heart rate and blood pressure oscillate throughout the day in phase with these circulating factors, being higher in the morning and decreasing during the evening. ${ }^{16,17}$
Endogenous thrombolytic activity and platelet aggregability also follow a circadian pattern. ${ }^{18}$ The plasma levels of fibrinogen and plasminogen activator inhibitor-1 activity increase between 6 am and noon, whereas antithrombin levels and the activity of tissue-type plasminogen activators decrease during the morning. ${ }^{19,20}$ This fact suggests a thrombogenic natural status during the first hours of the day that turns into a physiological pro-fibrinolytic status in the evening hours.

Indeed, an internal circadian network has been identified in cardiovascular cells, including vascular, smooth muscle cells, endothelial cells, and cardiomyocytes. ${ }^{21}$ This molecular mechanism, intrinsic to the cardiomyocyte, is a protein complex that induces circadian gene expression oscillations that persist even in isolated, cultured myocytes, demonstrating the independence of this circadian system from the central one. ${ }^{22}$ The internal circadian clock modulates cardiovascular physiology by regulating heart rate, metabolism, and even myocyte growth or repair abilities. ${ }^{23}$

Preclinical studies suggest that mammalian circadian patterns are controlled by both internal and external factors. ${ }^{24,25}$ Light stimulus is the strongest time-controller for the circadian central clock, which regulates the neurohumoral secretion of several factors that influence the peripheral autonomous circadian clocks, such as that of the cardiomyocyte. ${ }^{26}$

\section{The circadian clock and cardiovascular pathology}

This correlation between the cardiovascular system and the circadian clock obviously implicates a relevant role of endogenous rhythms, not only in cardiac physiology, but in both vascular and heart disease as well. Circadian clock-mutant rodents exhibit a reduction in vasculoprotective signals, an accelerated time in occlusion after acute experimental thrombosis, ${ }^{27}$ aberrant vascular remodeling, and significant susceptibility to thrombosis in response to a chronic reduction in blood flow. ${ }^{28,29}$ Cardiac fibrosis has also been demonstrated to be related to the circadian clock, being lower in wild-type mouse hearts than in cardiomyocyte circadian clock-mutant specimens, ${ }^{4}$ suggesting an inherent effect on cardiac remodeling after ischemia.

Clinical consequences of circadian cardiovascular variations in humans have already been extensively studied. Multiple epidemiological studies proved higher morning incidences of sudden death, ventricular arrhythmias, cardiogenic shock, stroke, aortic dissection, and abdominal aortic aneurysm rupture. ${ }^{30-37}$ The frequency of cardiovascular event 
onset follows a marked circadian rhythm, with a peak from 6 am to noon, occurring simultaneously with the morning circadian increases in platelet aggregability, heart rate, and blood pressure..$^{8,37}$ Overall, there is compelling evidence to show that several cardiovascular pathological states are significantly influenced by the circadian rhythm. ${ }^{38}$

\section{Circadian rhythm and ischemial reperfusion}

Despite our vast knowledge of the circadian variations of pathophysiological cardiovascular states, the potential circadian influence on human tolerance to ischemia/reperfusion (I/R) has not been systematically scrutinized until recently, and is only now a major focus in cardiovascular research. In mammalian hearts, there is activation of an intrinsic defense mechanism encompassed by several protein pathways in response to ischemic events. ${ }^{39}$ Depending on the effectiveness and degree of activation of those survival molecules, cardiomyocytes will either survive or die following an I/R event. Pre-clinical studies determined that the expression of some proteins from these survival pathways exert a robust circadian oscillation. ${ }^{40,41}$

The first evidence of the effect of the time of the day of AMI onset on infarct size was revealed by Durgan et al. ${ }^{4}$ They performed an animal study with mice that were exposed to a left anterior descending coronary artery occlusion followed by reperfusion at different times of day. Those animals in which I/R was initiated during the sleep-to-wake transition displayed greater degrees of short-term necrosis and longterm fibrosis, as well as lower ejection fractions, compared to those subjected to $\mathrm{I} / \mathrm{R}$ at the wake-to-sleep transition. In addition, cardiomyocyte-specific circadian clock-mutant rodents were analyzed, and it was discovered that infarct size differences, depending on the time of day of the ischemia, disappeared when the circadian internal clock was knocked out.

It was unknown at this point whether the spontaneous variation of infarct size found in those animals might be extended to other mammalian species such as humans. In this regard, our group has reported on the impact of the time of day of STEMI-onset on infarct size for the first time in humans. ${ }^{5}$

Suárez-Barrientos et $\mathrm{al}^{5}$ carried out a retrospective, singlecenter analysis including 811 patients with a first STEMI revascularized by any means. Infarct size was estimated by both creatine kinase (CK) and troponin (Tp I) peak enzyme release. To explore the relationship between enzyme concentrations and time of symptom onset, multivariate regression splines were used; the resulting curves are shown in Figures 1 and 2. It is clear that both the $\mathrm{CK}$ and Tp I peak releases reached their maximum between 6 am and noon. That circadian pattern of biomarker peak release was independent of any other variables that might strongly influence infarct size, such as ischemia localization, or time between symptom onset and revascularization. Further supporting these results, CK- and Tp I-adjusted differences between groups were compared performing a multivariate regression analysis between patients who suffered the STEMI onset at the dark-to-light transition and those for whom onset occurred in all other periods of the day together. Infarct size was significantly larger in the 6 am to noon group, with higher CK and Tp I levels in those with STEMI onset at the night-to-day transition, which meant an expected increase in infarct size of about $20 \%$. These results agreed with the conclusions of Durgan et al, ${ }^{23}$ suggesting that the fluctuant cardioprotection observed in rodents is also present in humans, and reinforcing the firmness of both groups' findings. This study represented the first documentation of circadian fluctuations in spontaneous cardioprotection in humans with STEMI.

More recently, two independent studies have replicated our data in different cohorts, ${ }^{42,43}$ both confirming that infarct sizes in STEMI patients display a circadian variation. Reiter et al studied a group of patients admitted for their first STEMI. ${ }^{42}$ The original population chosen was large (approximately 1000 patients), but they decided to exclude more than $80 \%$ of the population from the actual analysis for different reasons, and the final study population was a rather small group of patients (165). The study found larger infarct sizes during the night period, in contrast to SuárezBarrientos et al and Durgan et al's work, which found larger infarctions in the night-to-day transition. Differences between Suárez-Barrientos et al and Reiter et al's results on the time of day at which the necrosis is larger may be due to a significant difference in the sample size and exclusion criteria.

Reiter et al and Durgan et al's studies had the main limitation of being retrospective analyses. A recently published study by Arroyo-Ucar et $\mathrm{al}^{43}$ was the first prospective document dealing with this issue. Arroyo-Ucar et al included 108 consecutive STEMI patients who were revascularized by primary angioplasty. Infarct sizes were determined by peak Tp I release. They divided the sample into two groups, depending on the time of symptom onset. Patients with STEMI onset between midnight and midday presented approximately $20 \%$ higher Tp I peak concentrations than those in whom STEMI onset occurred in the midday to midnight period. These results were confirmed in the multivariate analysis, with the time of day of symptom onset being a strong independent predictor of infarct size. 


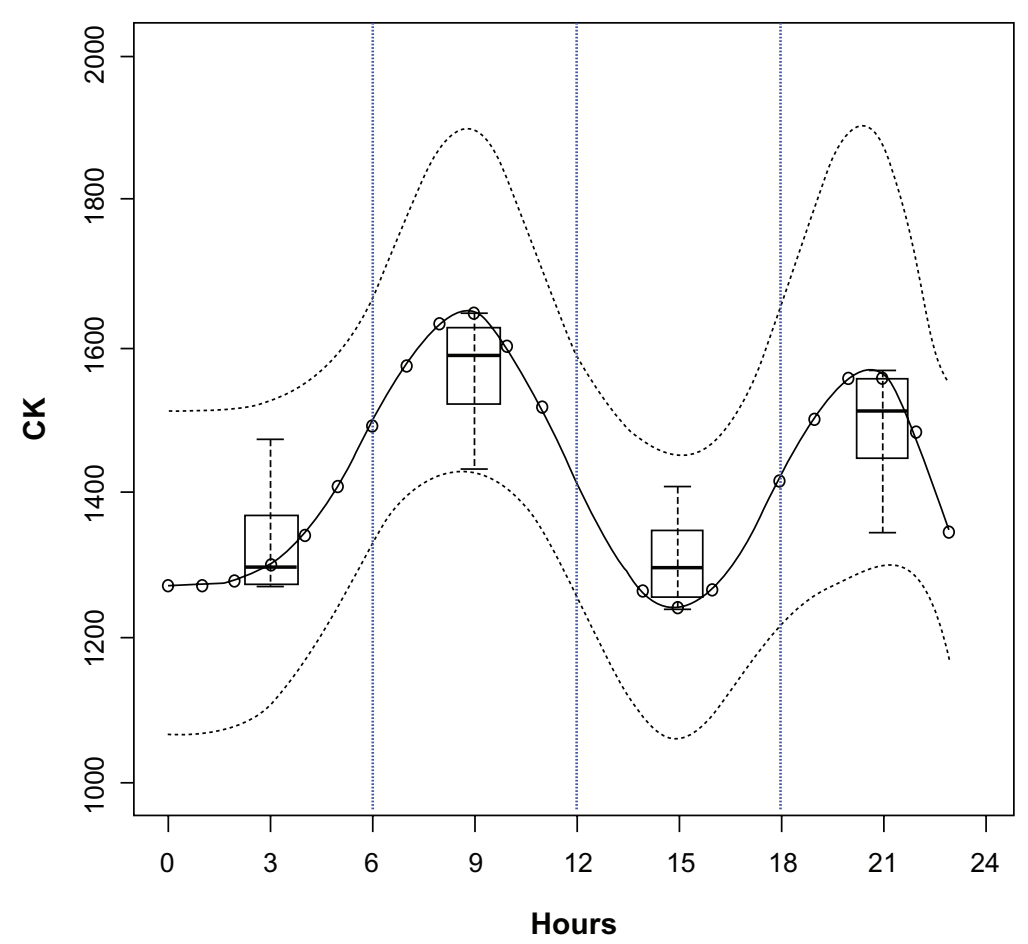

Figure I Adjusted geometric means and 95\% confidence interval of peak concentrations of creatine kinase (CK) estimated by regression splines.

Note: The fitted curve corresponds to an average time of ischemia $=230.48$ minutes and reference levels for the rest of the confounders in the linear model (see text). The spline covariates matrix used in the linear model was obtained using three cubic B-spline basis functions defined for the vector of knots at times $t=0,4,9,15,22$, and 24 . Boxplots represent curve estimated peak enzyme concentrations in each of the previously specified periods (midnight-6 am, 6 am-noon, noon- 6 pm, 6 pm, midnight).

Copyright (c) 20II, BMJ. Reproduced with permission from Suárez-Barrientos A, López-Romero P, Vivas D, et al. Circadian variations of infarct size in acute myocardial infarction. Heart. 2011;97(12):970-976. ${ }^{5}$

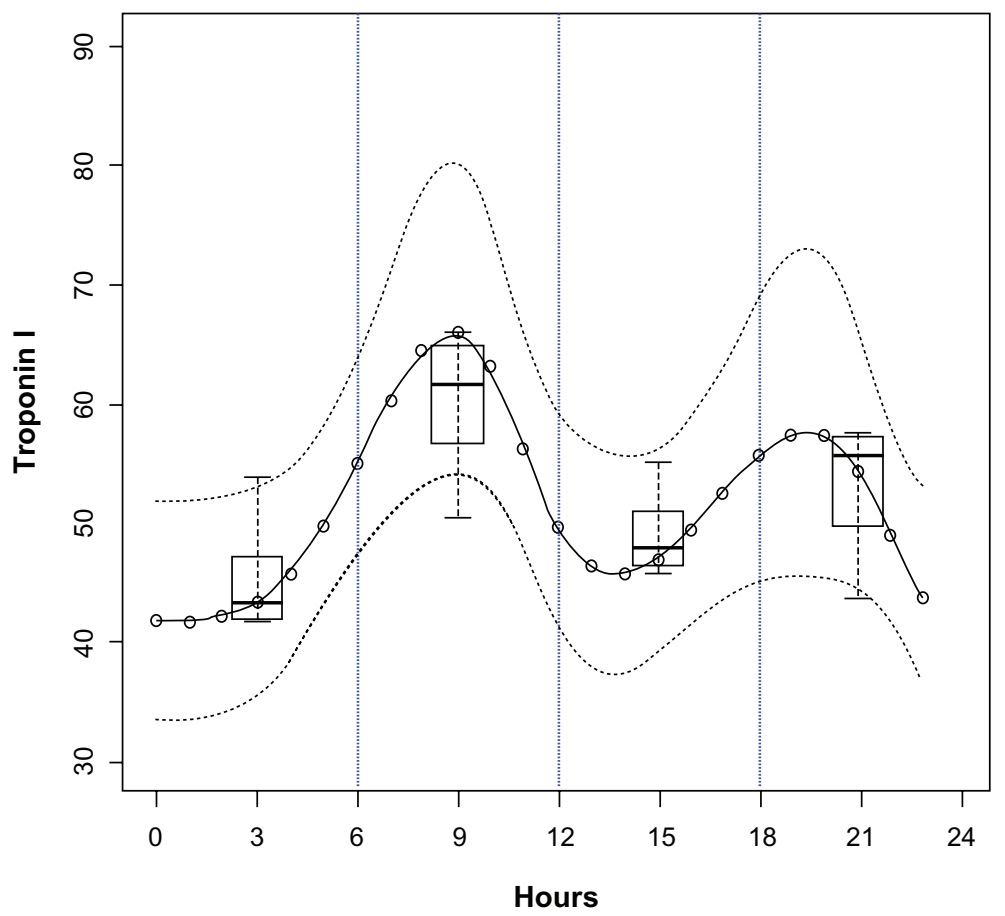

Figure 2 Adjusted geometric means and 95\% confidence interval of peak concentrations of troponin-I estimated by regression splines.

Notes: The fitted curve corresponds to an average time of ischemia $=230.48$ minutes and reference levels for the rest of the confounders in the linear model (see text). The spline covariates matrix used in the linear model was obtained using three cubic B-spline basis functions defined for the vector of knots at times $t=0,4,10,12,21$, and 24 . Boxplots represent curve estimated peak enzyme concentrations in each of the previously specified periods (midnight-6 am, 6 am-noon, noon- 6 pm, 6 pm, midnight). Copyright (c) 20II, BMJ. Reproduced with permission from Suárez-Barrientos A, López-Romero P, Vivas D, et al. Circadian variations of infarct size in acute myocardial infarction. Heart. 20I I;97(I2):970-976. ${ }^{5}$ 
The three studies of humans so far published in this regard are limited by infarct-size assessment methods. It was in all cases evaluated by a surrogate marker - peak rise in enzyme levels. Even though it has been systematically reported that this methodology is accurate and correlates with other methods, ${ }^{44}$ a direct evaluation of AMI size would have measured infarct size more precisely. Of greatest relevance is the fact that all three studies agree that there is a strong relationship between the time of day of symptom onset and infarct size.

\section{Circadian variations and reperfusion}

Several other studies have also proposed that the time of day of revascularization in patients with STEMI may influence infarct size. De Luca et $\mathrm{al}^{44}$ studied this association, concluding that patients treated between 4 am and 8 am by primary percutaneous coronary intervention had a trend toward larger infarctions, although AMI size was not normalized to important variables like time of ischemia or culprit artery. Reiter et al also described this phenomenon, reporting higher peak enzyme levels when time of reperfusion occurred at 5 am.

Circadian variations of revascularization outcomes have also been described. Magid et al studied 33,647 patients treated with percutaneous coronary intervention. ${ }^{45}$ They observed that those patients presenting during "off-hours" (weekdays from $5 \mathrm{pm}$ to $7 \mathrm{am}$ and on weekends) had significantly higher adjusted in-hospital mortality than patients presenting during "regular" hours (weekdays from 7 am to $5 \mathrm{pm}$ ). These conclusions were shared by other studies that found significantly higher rates of angioplasty failure and inhospital mortality from $6 \mathrm{pm}$ to 8 am compared to the time range from 8 am to $6 \mathrm{pm} .{ }^{46,47}$ This fact may be due to different causes, such as longer door-to-balloon times during the night or a nighttime delay in medical assistance being received.

Medical reperfusion by fibrinolysis also depends on the circadian clock. Tissue plasminogen activator efficacy has a clear circadian pattern, measured by the velocity necessary to produce a patent coronary artery, being higher from noon to midnight. ${ }^{48}$ The efficacy of thrombolytic therapy with streptokinase has also been described to be higher in the late afternoon and early evening hours. ${ }^{49}$ Goldhammer et al even reported that, in a multiple regression analysis, the independent factor with the greatest impact on successful reperfusion with streptokinase was the time of day of thrombolysis $(P=0.037)$, followed by the time of ischemia. ${ }^{49}$

Many other works disagree on this issue, finding similar outcomes in reperfusion during any period of the day. ${ }^{50-52}$ Controversy and divergent results are natural, since reperfusion outcomes depend on many other variables, such as operator experience, time of ischemia, or the culprit artery. Circadian influences on cardiovascular system may also play a role, as it contributes to a prothrombotic status during the first hours of the morning, and to natural fibrinolytic activity in the evening, ${ }^{53,54}$ with the technical success or failure of primary angioplasty depending on the time of performance.

\section{Clinical significance}

Left ventricular (LV) ejection fractions and/or LV volumes were previously the established predictors of mortality in patients with coronary artery disease and severe LV dysfunction. Contrast-enhanced magnetic resonance imaging allows one to delineate infarct size precisely, and it has been proven that myocardial infarct size correlates well with LV ejection fractions and end-systolic volume index. Indeed, infarct size evaluated by magnetic resonance imaging is a stronger predictor of future cardiac event development and correlates directly with LV remodeling. 1,55,56 Therefore, the potential association between circadian clock and infarct size advocates the admission of time of day as a new prognostic factor in patients suffering from AMI. Those presenting during the sleep-to-wake transition seem to have a worse prognosis compared to those that occur during the rest of the day, creating a new aspect to optimally risk-stratifying patients after AMI.

Like any other factor influencing infarct size and subsequent AMI clinical outcomes, infarct circadian onset becomes a new therapeutic target. As it seems to be difficult and hazardous to alter the central or peripheral circadian clock, it seems reasonable to deal with those humoral and physiological factors that link the circadian clock with cardiovascular events. As the circadian influence on blood pressure and heart rate is well known, it has already been investigated whether traditional cardiovascular therapies can modify daily patterns of blood pressure or heart rate peaks in the morning, lowering cardiovascular risk in this period of the day. Aldosterone blockers reduce heart rate and improve the parasympathetic component of heart rate variability, which are the greatest effects during the morning hours, coinciding with the circadian pattern of cardiac events. ${ }^{57}$ It has also been proven that treatment with $\beta$-blocker agents abolishes the dark-to-light transition peak incidence of both AMI and sudden death. ${ }^{58,59}$

Chronotherapeutics attempt to deliver the drug in higher concentrations during the time of greatest need during the day, which may be achieved by altering dosing patterns. The optimal object seemed to reach the peak effect of cardiovascular treatment during the night-to-day transition, without inducing the excessive lowering of the heart rate or blood pressure during the night, which could be detrimental. In this regard, different 
results have been obtained. Hermida et al described that bedtime antihypertensive therapy, compared to conventional treatment upon waking, more effectively improved blood pressure control and significantly reduced cardiovascular disease morbidity and mortality ${ }^{60}$ Evening lisinopril- or quinapril-isolated administration seems to more greatly reduce blood pressure than in the early morning, without inducing excessive hypotension during sleep. ${ }^{61,62}$ By contrast, a variety of other antihypertensive agents, including b-blockers, ${ }^{63}$ ACE inhibitors, and calcium channel blockers, ${ }^{64}$ do not change circadian patterns of blood pressure depending on the dosing time. ${ }^{65,66}$ Efforts need to be focused on suitable forms of drug delivery that may appropriately cover night-to-day transition hours, such as doxazosine or verapamil, ${ }^{67,68}$ when dosed in the evening. Nevertheless, the potential effects of cardiovascular agents on circadian infarct size may be attributed to some other mechanism, not just heart rate or blood pressure variation, such as a blockage of the morning surge in sympathetic activity in the case of $\beta$-receptor antagonist therapy. Indeed, other humoral factors such as melatonin may play a role in circadian cardioprotection. This is an attractive target for further investigation and could lead to the development of novel therapy approaches.

Obviously, all of these treatment strategies are focused on those patients with known cardiovascular risk factors or with previous ischemic myocardial disease. The question now is if it is possible to palliate circadian influence on infarct size and prognosis during the acute ischemic event, modulating both humoral factors and internal circadian clock mechanisms, allowing us to control spontaneous cardio-aggression during the morning. In that respect, wide research must be performed in order to clarify and reveal the intimate course of circadian spontaneous cardioprotection during the rest of the day.

Finally, infarct size is one of the most accurate variables used as the endpoint of clinical trials testing novel cardioprotective strategies. ${ }^{2}$ As a result, the time of AMI onset should be carefully collected and analyzed as a new variable in these studies, since it influences infarct size, and its results must be considered in order to avoid a potential time-of-day bias.

\section{Disclosure}

The authors report no conflicts of interest in this work.

\section{References}

1. Wu E, Ortiz JT, Tejedor P, et al. Infarct size by contrast enhanced cardiac magnetic resonance is a stronger predictor of outcomes than left ventricular ejection fraction or end-systolic volume index: prospective cohort study. Heart. 2008;94(6):730-736.

2. Pitcher A, Ashby D, Elliott P, Petersen SE. Cardiovascular MRI in clinical trials: expanded applications through novel surrogate endpoints. Heart. 2011;97(16):1286-1292.
3. Cohen MC, Rohtla KM, Lavery CE, Muller JE, Mittleman MA. Meta-analysis of the morning excess of acute myocardial infarction and sudden cardiac death. Am J Cardiol. 1997;79(11):1512-1516.

4. Durgan DJ, Pulinilkunnil T, Villegas-Montoya C, et al. Short communication: ischemia/reperfusion tolerance is time-of-daydependent: mediation by the cardiomyocyte circadian clock. Circ Res. 2010;106(3):546-550.

5. Suárez-Barrientos A, López-Romero P, Vivas D, et al. Circadian variations of infarct size in acute myocardial infarction. Heart. 2011; 97(12):970-976.

6. Kwon I, Choe HK, Son GH, Kim K. Mammalian Molecular Clocks. Exp Neurobiol. 2011;20(1):18-28.

7. Saini C, Suter DM, Liani A, Gos P, Schibler U. The mammalian circadian timing system: synchronization of peripheral clocks. Cold Spring Harb Symp Quant Biol. December 16 2011; [Epub ahead of print.]

8. Albrecht U. Circadian clocks in mood-related behaviors. Ann Med. 2010;42(4):241-251.

9. Degaute JP, Van Cauter E, van de Borne P, Linkowski P. Twenty-fourhour blood pressure and heart rate profiles in humans. A twin study. Hypertension. 1994;23(2):244-253.

10. Linsell CR, Lightman SL, Mullen PE, Brown MJ, Causon RC. Circadian rhythms of epinephrine and norepinephrine in man. J Clin Endocrinol Metab. 1985;60(6):1210-1215.

11. Turton MB, Deegan T. Circadian variations of plasma catecholamine, cortisol and immunoreactive insulin concentrations in supine subjects. Clin Chim Acta. 1974;55(3):389-397.

12. Hurwitz S, Cohen RJ, Williams GH. Diurnal variation of aldosterone and plasma renin activity: timing relation to melatonin and cortisol and consistency after prolonged bed rest. J Appl Physiol. 2004;96(4):1406-1414.

13. Armbruster H, Vetter W, Beckerhoff R, Nussberger J, Vetter H, Seigenthaler W. Diurnal variations of plasma aldosterone in supine man: relationship to plasma renin activity and plasma cortisol. Acta Endocrinol (Copenh). 1975;80(1):95-103.

14. Pevet P, Challet E. Melatonin: both master clock output and internal time-giver in the circadian clocks network. J Physiol Paris. 2011; 105(4-6): 170-182.

15. Reiter RJ, Tan DX. Melatonin and cardiac pathophysiology. Heart Metab. 2009;44:31-34.

16. Richards AM, Nicholls MG, Espiner EA, Ikram H, Cullens M, Hinton D. Diurnal patterns of blood pressure, heart rate and vasoactive hormones in normal man. Clin Exp Hypertens A. 1986;8(2):153-166.

17. Rudic RD, Fulton DJ. Pressed for time: the circadian clock and hypertension. J Appl Physiol. 2009;107(4):1328-1338.

18. Tofler GH, Brezinski D, Schafer AI, et al. Concurrent morning increase in platelet aggregability and the risk of myocardial infarction and sudden cardiac death. N Engl J Med. 1987;316(24):1514-1518.

19. Petralito A, Mangiafico RA, Gibiino S, Cuffari MA, Miano MF, Fiore CE. Daily modification of plasma fibrinogen platelets aggregation, Howell's time, PTT, TT, and antithrombin III in normal subjects and in patients with vascular disease. Chronobiologia. 1982;9(2):195-201.

20. Angleton P, Chandler WL, Schmer G. Diurnal variation of tissue-type plasminogen activator and its rapid inhibitor (PAI-1). Circulation. 1989;79(1):101-106.

21. Davidson AJ, London B, Block GD, Menaker M. Cardiovascular tissues contain independent circadian clocks. Clin Exp Hypertens. 2005;27(2-3):307-311.

22. Durgan DJ, Hotze MA, Tomlin TM, et al. The intrinsic circadian clock within the cardiomyocyte. Am J Physiol Heart Circ Physiol. 2005;289(4):H1530-H1541.

23. Durgan DJ, Young ME. The cardiomyocyte circadian clock: emerging roles in health and disease. Circ Res. 2010;106(4):647-658.

24. Martinez-Nicolas A, Ortiz-Tudela E, Madrid JA, Rol MA. Crosstalk between environmental light and internal time in humans. Chronobiol Int. 2011;28(7):617-629.

25. Lowrey PL, Takahashi JS. Genetics of circadian rhythms in mammalian model organisms. Adv Genet. 2011;74:175-230. 
26. Damiola F, Le Minh N, Preitner N, Kornmann B, Fleury-Olela F, Schibler U. Restricted feeding uncouples circadian oscillators in peripheral tissues from the central pacemaker in the suprachiasmatic nucleus. Genes Dev. 2000;14(23):2950-2961.

27. Westgate EJ, Cheng Y, Reilly DF, et al. Genetic components of the circadian clock regulate thrombogenesis in vivo. Circulation. 2008;117(16):2087-2095.

28. Anea CB, Zhang M, Stepp DW, et al. Vascular disease in mice with a dysfunctional circadian clock. Circulation. 2009;119(11): $1510-1517$.

29. Viswambharan H, Carvas JM, Antic V, et al. Mutation of the circadian clock gene Per2 alters vascular endothelial function. Circulation. 2007;115(16):2188-2195.

30. Muller JE, Tofler GH, Stone PH. Circadian variation and triggers of onset of acute cardiovascular disease. Circulation. 1989;79(4):733-743.

31. Mehta RH, Manfredini R, Hassan F, et al. Chronobiological patterns of acute aortic dissection. Circulation. 2002;106(9):1110-1115.

32. Arntz HR, Willich SN, Schreiber C, Brüggemann T, Stern R, Schultheiss HP. Diurnal, weekly and seasonal variation of sudden death. Population-based analysis of 24,061 consecutive cases. Eur Heart J. 2000;21(4):315-320.

33. Morning peak in the incidence of myocardial infarction: experience in the ISIS-2 trial. ISIS-2 (Second International Study of Infarct Survival) Collaborative Group. Eur Heart J. 1992;13(5):594-598.

34. Englund A, Behrens S, Wegscheider K, Rowland E. Circadian variation of malignant ventricular arrhythmias in patients with ischemic and nonischemic heart disease after cardioverter defibrillator implantation. European 7219 Jewel Investigators. J Am Coll Cardiol. 1999;34(5):1560-1568.

35. Manfredini R, Boari B, Gallerani M, et al. Chronobiology of rupture and dissection of aortic aneurysms. J Vasc Surg. 2004;40(2):382-388.

36. Elliott WJ. Circadian variation in the timing of stroke onset: a meta-analysis. Stroke. 1998;29(5):992-996.

37. Gnecchi-Ruscone T, Piccaluga E, Guzzetti S, Contini M, Montano N, Nicolis E. Morning and Monday: critical periods for the onset of acute myocardial infarction. The GISSI 2 Study experience. Eur Heart $J$. 1994;15(7):882-887.

38. Takeda N, Maemura K. Circadian clock and cardiovascular disease. J Cardiol. 2011;57(3):249-256.

39. Hausenloy DJ, Yellon DM. New directions for protecting the heart against ischaemia-reperfusion injury: targeting the Reperfusion Injury Salvage Kinase (RISK)-pathway. Cardiovasc Res. 2004;61(3):448-460.

40. Iitaka C, Miyazaki K, Akaike T, Ishida N. A role for glycogen synthase kinase-3beta in the mammalian circadian clock. J Biol Chem. 2005;280(33):29397-29402.

41. Miura T, Miki T. GSK-3beta, a therapeutic target for cardiomyocyte protection. Circ J. 2009;73(7):1184-1192.

42. Reiter R, Swingen C, Moore L, Henry TD, Traverse JH. Circadian dependence of infarct size and left ventricular function after ST elevation myocardial infarction. Circ Res. 2011;110(1):105-110.

43. Arroyo Úcar E, Dominguez-Rodriguez A, Abreu-Gonzalez P. Influencia de la variabilidad diurna en el tamaño del infarto agudo de miocardio [Influence of diurnal variation in the size of acute myocardial infarction]. Med Intensiva. 2012;36(1):11-14. Spanish.

44. De Luca G, Suryapranata H, Ottervanger JP, et al. Circadian variation in myocardial perfusion and mortality in patients with ST-segment elevation myocardial infarction treated by primary angioplasty. $\mathrm{Am}$ Heart J. 2005;150:1185-1189.

45. Magid DJ, Calonge BN, Rumsfeld JS, et al. Relation between hospital primary angioplasty volume and mortality for patients with acute MI treated with primary angioplasty vs thrombolytic therapy. JAMA. 2000;284:3131-3138.

46. Henriques JP, Haasdijk AP, Zijlstra F, Zwolle Myocardial Infarction Study Group. Outcome of primary angioplasty for acute myocardial infarction during routine duty hours versus during off-hours. $J \mathrm{Am}$ Coll Cardiol. 2003;41(12):2138-2142.
47. Dominguez-Rodriguez A, Garcia-Gonzalez M, Abreu-Gonzalez P. Outcome of primary angioplasty for ST-segment elevation myocardial infarction during routine duty hours versus during off-hours. Results of a single-center in Spain. Int J Cardiol. 2007;119(2):227-229.

48. Kurnik PB. Circadian variation in the efficacy of tissue-type plasminogen activator. Circulation. 1995;91(5):1341-1346.

49. Goldhammer E, Kharash L, Abinader EG. Circadian fluctuations in the efficacy of thrombolysis with streptokinase. Postgrad Med J. 1999;75(889):667-671.

50. Garot P, Juliard JM, Benamer H, Steg PG. Are the results of primary percutaneous transluminal coronary angioplasty for acute myocardial infarction different during the "off" hours? Am J Cardiol. 1997; 79(11):1527-1529.

51. Zahn R, Schiele R, Seidl K, et al. Daytime and nighttime differences in patterns of performance of primary angioplasty in the treatment of patients with acute myocardial infarction. Maximal Individual Therapy in Acute Myocardial Infarction (MITRA) Study Group. Am Heart J. 1999;138(6 Pt 1):1111-1117.

52. Mingo S, Goicolea J, Nombela L, et al. Angioplastia primaria en nuestro medio. Análisis de los retrasos hasta la reperfusión, sus condicionantes y su implicación pronóstica [Primary percutaneous angioplasty. An analysis of reperfusion delays, their determining factors and their prognostic implications]. Rev Esp Cardiol. 2009;62(1):15-22. Spanish.

53. Grimaudo V, Hauert J, Bachmann F, Kruithof EK. Diurnal variation of the fibrinolytic system. Thromb Haemost. 1988;59(3):495-499.

54. Andreotti F, Davies GJ, Hackett DR, et al. Major circadian fluctuations in fibrinolytic factors and possible relevance to time of onset of myocardial infarction, sudden cardiac death and stroke. Am J Cardiol. 1988;62(9):635-637.

55. Kelle S, Roes SD, Klein C, et al. Prognostic value of myocardial infarct size and contractile reserve using magnetic resonance imaging. $J \mathrm{Am}$ Coll Cardiol. 2009;54(19):1770-1777.

56. Watzinger N, Lund GK, Higgins CB, Wendland MF, Weinmann HJ, Saeed M. The potential of contrast-enhanced magnetic resonance imaging for predicting left ventricular remodeling. J Magn Reson Imaging. 2002;16(6):633-640.

57. Yee KM, Pringle SD, Struthers AD. Circadian variation in the effects of aldosterone blockade on heart rate variability and QT dispersion in congestive heart failure. J Am Coll Cardiol. 2001;37(7):1800-1807.

58. Willich SN, Linderer T, Wegscheider K, Leizorovicz A, Alamercery I, Schröder R. Increased morning incidence of myocardial infarction in the ISAM Study: absence with prior beta-adrenergic blockade. ISAM Study Group. Circulation. 1989;80(4):853-858.

59. Peters RW, Muller JE, Goldstein S, Byington R, Friedman LM. Propranolol and the morning increase in the frequency of sudden cardiac death (BHAT Study). Am J Cardiol. 1989;63(20):1518-1520.

60. Hermida RC, Ayala DE, Mojón A, Fernández JR. Influence of circadian time of hypertension treatment on cardiovascular risk: results of the MAPEC study. Chronobiol Int. 2010;27(8):1629-1651.

61. Macchiarulo C, Pieri R, Mitolo DC, Pirrelli A. Management of antihypertensive treatment with Lisinopril: a chronotherapeutic approach. Eur Rev Med Pharmacol Sci. 1999;3(6):269-275.

62. Palatini P, Racioppa A, Raule G, Zaninotto M, Penzo M, Pessina AC. Effect of timing of administration on the plasma ACE inhibitor activity and the antihypertensive effect of quinapril. Clin Pharmacol Ther. 1992;52(4):378-383.

63. Sundberg S, Luurila OJ, Kohvakka A, Gordin A. The circadian heart rate but not blood pressure profile is influenced by the timing of ß-blocker administration in hypertensives. Eur J Clin Pharmacol. 1991;40(4):435-436.

64. Mengden T, Binswanger B, Spühler T, Weisser B, Vetter W. The use of self-measured blood pressure determinations in assessing dynamics of drug compliance in a study with amlodipine once a day, morning versus evening. J Hypertens. 1993;11(12):1403-1411.

65. Lemmer B. Differential effects of antihypertensive drugs on circadian rhythm in blood pressure from the chronobiological point of view. Blood Press Monit. 1996;1:161-169. 
66. Voogel AJ, van der Meulen JH, van Montfrans GA. Effects of antihypertensive drugs on the circadian blood pressure profile. J Cardiovasc Pharmacol. 1996;28(3):463-469.

67. Pickering TG, Levenstein M, Walmsley P. Nighttime dosing of doxazosin has peak effect on morning ambulatory blood pressure. Results of the HALT Study. Hypertension and Lipid Trial Study Group. Am J Hypertens. 1994;7(9 Pt 1):844-847.
68. White WB, Anders RJ, MacIntyre JM, Black HR, Sica DA. Nocturnal dosing of a novel delivery system of verapamil for systemic hypertension. Verapamil Study Group. Am J Cardiol. 1995;76(5): 375-380.

\section{Publish your work in this journal}

ChronoPhysiology and Therapy is an international, peer-reviewed, open access journal focusing on research into the cyclic variations and rhythmicity in physiological processes in the body and the research and development and optimal timing of administration of therapeutic targets to achieve improved outcomes and quality of life for the patient. The manuscript management system is completely online and includes a very quick and fair peer-review system. Visit http://www.dovepress.com/ testimonials.php to read real quotes from published authors. 